\title{
Duesberg and the new view of HIV
}

\section{This journal has offered Dr Peter Duesberg and his associates an opportunity to comment on last week's publications suggesting that the immune system reacts hyperactively to HIV infection.}

THE publication last week of two important articles on the dynamics of the infection of people by HIV is agreed to have been a important landmark in the process of understanding the disease called AIDS, but not everybody will be aware of that. Reporting of the event has been curiously selective. In particular, the British newspaper The Sunday Times, which as recently as a year ago was replete with accounts of how HIV can have little or nothing to do with the causation of AIDS, chose not even to mention the new developments in last Sunday's edition.

Is it planning a majoraccount of how it came to be so misled, thus to mislead its readers? Or is it waiting for a sign from Professor Peter Duesberg, of Berkeley, California, who started the hare the newspaper followed eagerly for two years?

The reasons why the new developments are (or should be) an embarrassment for Duesberg are simply put. Almost from the outset of AIDS as a recognized disease in the early 1980 s, the objective index of an infected person's state of health has been the concentration in the blood of T lymphocytes carrying the CD4 antigen. The more advanced the infection, the smaller the concentration of $\mathrm{CD}^{+}$cells.

But Duesberg was quick to point to a paradox in the observations: although the concentration of $\mathrm{CD}^{+}$cells might decline with the persistence of infection, there was no dramatic increase of the frequency of infected $T$ cells as infection gave way to overt disease. Cell death by inter-cellular infection could hardly be consistent with that state of affairs.

In essence, the new developments resolve the paradox by showing that the $T$ cells in an infected person's blood are likely to have been created only in the few days previously. There will not have been time enough for more than a small proportion of them to have become infected, while those that harbour virus will be killed off very soon. So the scarcity of T cells from which virus can be recovered in test-tube experiments is consistent with the assertion that the immune system is inoverdrive from the onset of infection by HIV.

On this (new) view, the progressive decline of the $\mathrm{CD}^{+}$concentration with the duration of infection is rather a symptom of the underlying infection than the crux of its mechanism. What seems to matter is that there should be cells (including $T$ cells) somewhere in the body (the lymph nodes are likely candidates) from which virus particles continue to leak into the blood plasma.
In other words, Duesberg is right to have argued all along that the usually slow decline of $\mathrm{CD}^{+}$cells is not consistent with what one would expect from a specific cytotoxic viral mechanism. The explanation is that the $\mathrm{CD} 4^{+}$population in the blood at any time has been freshly created.

Despite this journal's severe line, some months ago, on Dueserg's right of reply to critics of his position, it is now in the general interest that his and his associates' views on the new developments should be made public. Duesberg was not available to take a single telephone call one day last week, nor able to return it, but one of his associates appeared to welcome the idea of a comment on the articles by Wei et al. and Ho et al. (Nature 373, 117-122 \& 123-126; 1995). That will be eagerly awaited and will be published with the usual provisos - that it is not libellous or needlessly rude, that it pertains to the new results and that it should not be longer than it needs to be.

Meanwhile, one important question stands out like a sore thumb: why, after more than a decade of research, has it only now emerged that the response of the immune system to infection by HIV is hyperactivity rather than the opposite? Simon WainHobson, writing in News and Views last week (Nature 373, 102; 1995), remarked that the investigators were able to reach their startling conclusions "by teaming up with mathematicians".

Intuitively, the sharp recovery of $\mathrm{CD} 4$ cells in the first few days after the administration of antiviral drugs pointed to their rapid production by the immune system. But in retrospect the good fortune of the investigators is clear. Only with the advent of highly specific drugs directed against HIV was it possible to cut off viral production so abruptly that the decline in plasma viraemia could form the basis for a model of viral production. New techniques for assaying the low levels of virus involved were also necessary; had the drugs been available only a few years earlier, these studies would have been impossible on that account.

In retrospect, the dynamics of the immune system would seem to be central to any consideration of the body's response to infection, by measles virus as well as HIV. And modelling of such processes as the production of lymphocytes (B as well as $T$ cells) in the immune response should be a relatively easy task (compared with, say, the appearance of endless molecular species in the evolution of a molecular cloud).

To be sure, immunologists are no stran- gers to quantitation in this spirit. And the involvement of mathematicians is simply explained by the authors' desire to be sure that even experts in this area approved of their data analysis. But the rarity of such studies says something depressing about the state of biology, for all its modernity. Despite the explosion in molecular knowledge (including molecular knowledge of viruses), the information to perform this kind of quantitative modelling is almost never available. In this case, the relevant data have emerged only after a decade of intensive research, fuelled by intense public interest in a most unpleasant pathogen. But virology is not the only field in which biology would benefit from more quantitative methods.

What more is to come? Now that the basis for the low $\mathrm{CD} 4^{+} \mathrm{T}$-cell count in AIDS patients is clear, further studies of the viral dynamics will be eagerly awaited. How much virus is produced by each productively infected cell? How fast is the virus produced by the lymph nodes? And what is responsible for killing the $\mathrm{CD}^{+} \mathrm{T}$ cells? If these last are indeed being destroyed by the $\mathrm{CD}^{+}$cells of the immune system, as WainHobson suggests (and this remains to be seen), it will undoubtedly lend further support to the idea that individuals who are repeatedly exposed to HIV while remaining unaffected are protected by their cytotoxic T lymphocytes (Rowland-Jones et al., $\mathrm{Na}$ ture Medicine 1, 59-64; 1995).

The search for effective antiviral therapy will also benefit. Already Wei et al. have followed the emergence of mutants resistant to one drug, and studies of others, alone and in combination, will surely follow. Here too, improved quantitation of the size of viral pools in different tissues, and their respective replication rates, will be vital.

What does this mean for basic research on AIDS, the cause eloquently advocated a year ago by Dr Bernie Fields (Nature 369, $95 ; 1994)$ ? Wei et al. and Ho et al. have provided the basis for a much more pointed programme of investigation from which, no doubt, a complete picture of the dynamics of this hitherto perplexing disease will emerge. A return to basics seems already to have happened. The prospects of therapy are much more difficult to tell, but has a fuller understanding ever failed to deliver improvements of technique? The danger for the Duesbergs of this world is that they will be left high and dry, championing a cause that will have ever fewer adherents as time passes. Now may be the time for them to recant.

John Maddox 